\title{
РЕАЛІЗАЦІЯ ПРОЕКТУ РОЗРОБКИ ПРОГРАМНОГО ЗАБЕЗПЕЧЕННЯ АВТОМАТИЗОВАНОГО КЕРУВАННЯ ПРОЦЕСОМ ФОРМУВАННЯ РОЗКЛАДУ НАВЧАЛЬНИХ ЗАНЯТЬ ЗАСОБАМИ ПАКЕТА
}

Сакалюк О.Ю.

Odessa National Academy of Food Technologies, Odessa, Ukraine

ORCID: https://orcid.org/0000-0002-5051-518X

E-mail: sakaliuk.olexiy@gmail.com

Copyright (C 2021 by author and the journal “Automation of technological and business - processes”.

This work is licensed under the Creative Commons Attribution International License (CC BY).

http://creativecommons.org/licanses/by/4.0

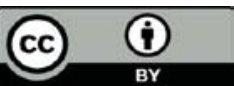

ONAFT

Open Access

DOI:

Анотація: Основою якісної організації освітнього процесу будь-якого навчального закладу, особливо закладу вищоі освіти є розклад навчальних занять. Якість підготовки спеціалістів в значній мірі залежить від методично правильного сформованого розкладу навчальних занять. Розклад навчальних занять та екзаменів є одним з найбільш відповідальних, трудомістких та стомлюючих завдань планування освітнього процесу [1].

Дослідники доклали значних зусиль для розробки універсальної автоматизованої системи керування процесом формування розкладу навчальних занять. Однак на сьогоднішній день немає ідеального рішення цієї проблеми, тому щзо ми повинні враховувати численні параметри та обмеження. Жодна з раніше розроблених систем не $\epsilon$ універсальною і не може задовольнити потреби всіх вищих навчальних закладів. Більшість систем використовують велику кількість вхідної інформації, щуо зберігається в базах даних. За допомогою складних алгоритмів на основі аналізу вхідної інформації складається розклад. Однак підсумковий графік не завжди ідеальний $і$ може потребувати багато ресурсів та часу. Розклад повинен задовольняти інтереси всіх учасників процесу [2]. Для розробки такої системи потрібно якісно розподілити роботи між виконавиями. Створення, будь-якого проекту завжди починається з його плануванням. Для виконання цих завдань уже давно багато компаній використовують системи управління проектами, які дозволяють ставити певні завдання, визначати людей, слідувати за процесом виконання завдань та виділенням необхідних ресурсів.

Завдання управління проектом програмного забезпечення може бути надзвичайно складним, виходячи з багатьох особистих, командних та організаџійних ресурсів. Якість програмного продукту залежить від процесу завершення проекту. Час затримок у проекті з розробки програмного забезпечення та низька продуктивність, як правило, впливають на кіниевий результат. Останнім часом еволюиія інструментів управління проектами як для програмних, так і для непрограмних додатків прискорюється швидкими темпами, а кількість доступних продуктів значно зросла. Щодня розробляється багато інструментів та програмного забезпечення для управління проектами, які допомагають менеджерам автоматизувати адміністрування окремих проектів або груп проектів протягом їх життевого ииклу [3].

Abstract: The basis of the qualitative organization of the educational process of any educational institution, especially the institution of higher education is a schedule of the courses. The quality of the training of specialists depends to a large extent on the methodically correct established schedule of the courses. The schedule of the courses and examinations is one of the most responsive, time-consuming and tedious tasks of planning the educational process [1].

Researchers have made great efforts to develop a universal automated control system for scheduling. However, to date there is no perfect solution to this problem, because we have to take into account numerous parameters and constraints. None of the previously developed systems is universal and can't meet the needs of all higher education institutions. Most systems use a large amount of input information stored in databases. With the help of complex algorithms, based on the analysis of input information, a course schedule is compiled. However, the resulting schedule is not always perfect and may require a lot of resources and time. The timetable must satisfy the interests of all participants in the process. The interests of some participants may conflict with the interests of other participants in the process [2]. To develop such a system, it is necessary to qualitatively distribute the work among the performers. Creating any project always starts with planning it. To accomplish these tasks, many companies have long used project management systems that allow them to set specific tasks, identify people, follow the process of performing tasks and allocate the necessary resources. 
The task of managing a software project can be an extremely complex one, drawing on many personal, team, and organizational resources. The quality of a software product is dependent on the process in which the project is completed. Time delays in software development project and low productivity tend to fall right to the bottom line. Recently, the evolution of project management tools for both software and non-software applications has been accelerating at a rapid pace, and the number of available products have grown significantly. There are many project management tools and software being developed every day to help managers to automate the administration of individual projects or groups of projects during their life-cycle [3].

Ключові слова: автоматизація, планування, управління проектами, Gantt Project, каскадний метод

Keywords: automation, scheduling, project management, Gantt Project, waterfall method

\section{1. Вступ}

Все більш популярною у всіх галузях стає методологія управління компанією з розподілом усієї роботи на проекти. Тому що керувати людьми - складно. Для успішного завершення проекту необхідні не тільки кваліфіковані та мотивовані співробітники, але і відповідні інструменти, які дозволять фіксувати досягнуті результати і своєчасно змінювати пріоритети. Обираючи інструменти, слід звернути увагу на те, щоб він міг складати діаграми Ганта і розподіляти повноваження та завдання між виконавцями з різними ролями. Таким інструментом $\epsilon$ Gantt Project - це програма, що призначена для планування проектів на основі побудови діаграм Гантта і діаграм типу PERT.

\section{2. Аналіз літературних даних і постановка проблеми}

Існує велика кількість визначень, що таке проект і якими характеристиками він наділений [4-6]. Аналізуючи всі визначення, то проект - це деяка задача, в якій є точний початок і точний кінець, метою якої є створення певної послуги, продукту чи досягнення певного результату.

За час існування проектного управління було створено чимало ефективних підходів, методів і стандартів, які можна взяти на озброєння. На даному етапі розвитку науки управління проектами виділяють такі методи управління проектами: Класичний проектний менеджмент, Agile, Scrum, Lean, Kanban, Six Sigma, PRINCE2 [7]. Bci ці методи мають як і сильні так і слабкі сторони. Управління проектами - це наука, але наука не найточніша. В умовах постійного потоку інформації, раптових змін і потреби в гнучкості робочих процесів, класичний підхід все менш популярний. Сучасний підхід до проектного менеджменту - це гнучкість робочих процесів, де в пріоритеті максимальна ефективність, контроль ресурсів і мінімізація втрат.

У даній області немає непорушних основ і універсальних рішень. Якщо менеджеру проекту вдасться знайти метод, який ідеально підходить для проекту - можна вважати, що йому повезло, адже більшості менш щасливих керівників доводиться прикладати зусилля для створення і налаштування власних систем управління проектами. Ці системи можуть бути складені з елементів існуючих систем або навіть створені абсолютно з нуля [8].

Після того, як було обрано підхід до проектного менеджменту, який підходить компанії - час обирати єдину систему. Система управління проектами (таск-менеджер) стане єдиним місцем для всіх робочих проектів та задач, для комунікації всередині команди і з клієнтами, для контролю часу, бюджету та завантаження команди. Існує велика кількість інструментів управління проектами, багато з них подібні, а багато з них зовсім різні між собою. До таких інструментів належать: Basecamp, Jira Software, asana, Trello, Padio, teamwork, Airtable, Microsoft Project, Gantt Project, Zoho та інші [9-10].

\section{3. Мета і завдання дослідження}

Основною метою дослідження є підготовка початкових (вхідних) даних для управління проектом та реалізація проекту засобами Gantt Project. Для досягнення мети потрібно виконати наступні завдання:

- підготовити початкові (вхідні) данні для управління проектом розробки та впровадження програмного забезпечення автоматизованого формування розкладу навчальних занять для ЗВО;

- створити проект в Gantt Project;

- заповнити список учасників проекту;

- додати задачі до проекту та дослідити діаграму Ганта.

\section{4. Методи і матеріали досліджень}

Для написання теоретичної частини роботи було використано такі методи дослідження:

- метод аналізу - проведено розкладання проекту на складові, а саме визначено суб'єктів проекту, основні задачі та строки поставлених задач;

- метод порівняння - проведено порівняння існуючих методів управління проектами та інструментів для управління проектами;

- метод дедукції - розмірковування над проектом проводилися за принципом від загального до окремого та було проведено декомпозицію проекту;

- метод класифікації - проведено групування робіт та розбиття їх на комплексні та елементарні.

Матеріалами дослідження $є$ аналіз процесу формування розкладу навчальних занять, математичні моделі та алгоритми отримані при дослідженні процесу формування розкладу навчальних занять а також інформація зібрана 3 опитувань працівників диспетчерської навчального відділу Одеської національної академії харчових технологій. 
http://www.atbp.onaft.edu.ua/

\section{5. Результати дослідження}

Метою проекту є розробка та впровадження програмного забезпечення автоматизованого формування розкладу навчальних занять для ЗВО. Даний проект відноситься до типу прикладних, тому що результатом є програмне забезпечення, яке вирішує проблему автоматизованого формування розкладу навчальних занять. До загальних особливостей проекту відносяться:

- особливості інтеграції - програмне забезпечення формування розкладу навчальних занять потрібно підключити до існуючої бази даних MySQL, в якій міститься інформація про дисципліни, аудиторії, учасників освітнього процесу та студентську угрупування. У зв'язку з тим, що програмне забезпечення повинно бути адаптивним, тобто працювати на різних пристроях, то в якості мови програмування було обрано РНР - мова сценаріїв (виконується на стороні серверу) $з$ відкритим вхідним кодом, що дає можливість швидкого створення web-cторінок. JavaScript - це мова програмування, що виконується на стороні клієнту та мова розмітки HTML та CSS;

- терміни доставки - обмеження у часі на виконання роботи, для даного випадку таким обмеженням $є$ дата початку навчального семестру;

- бюджетні обмеження - сума, запланована для інвестицій у проект, в даному випадку розробка та впровадження $є$ частиною дисертаційної роботи, тому всі роботи виконуються безкоштовно.

Модель життєвого циклу проекту розробки та впровадження програмного забезпечення схематично пояснює яким чином будуть виконуватися дії з розробки та впровадження програмного забезпечення, шляхом «послідовності» цих дій. Така послідовність може бути або не бути лінійною, оскільки фази можуть слідкувати одна за одною, повторюватися або відбуватися послідовно.

Найбільш очевидний шлях реалізації проекту - розбити його на фази або окремі завдання. Найпростіший інструмент проектного управління є чек-лист дій, які необхідно зробити для досягнення мети. За всю історію проектного управління було створено безліч різних методів управління проектами під практично будь-які потреби. Для різних проектів необхідні різні методи та інструменти. Головне зрозуміти, що найважливіше для проекту дедлайни, ресурси, дотримання процесу, або відразу кілька факторів - а потім вибрати метод управління проектом, орієнтований на досягнення цього показника. В якості методу управління було обрано класичний проектний менеджмент. Найбільш широко поширений метод управління проектами, заснований на так званому «водоспадному» (Waterfall) або каскадному циклі, при якому завдання передається послідовно по етапах, що нагадує потік, схематично це зображено на рис.1.

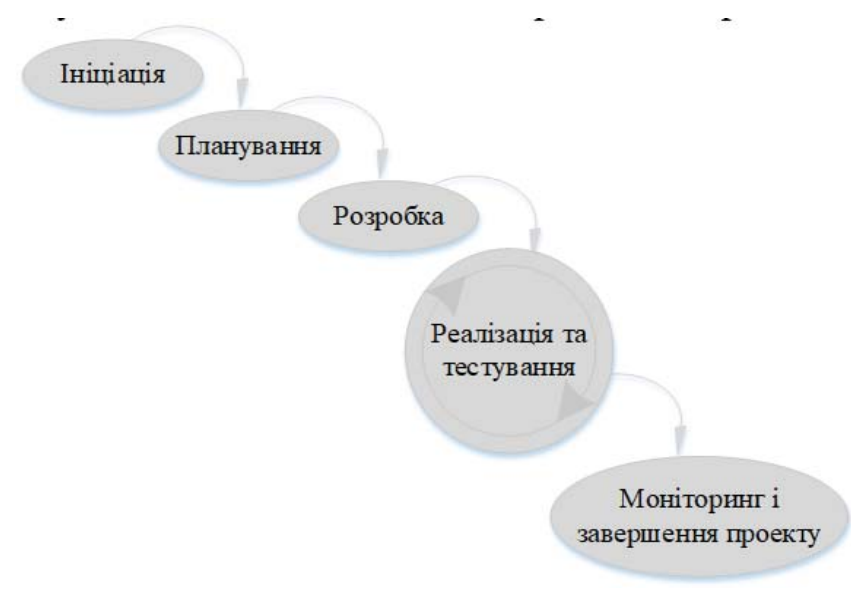

Рис. 1 - Схема класичного проектного управління

Зазвичай виділяють 5 етапів класичного проектного управління, але можна додавати і додаткові етапи, якщо того вимагає проект. 5 етапів традиційного менеджменту:

Eman 1. Iніuіація. Керівник проекту і команда визначають вимоги до проекту. На даному етапі часто проводяться наради та «Мозкові штурми», на яких визначається що ж повинен представляти із себе продукт проекту.

Eman 2. Планування. На даному етапі команда вирішує, як вона буде досягати мети, поставленої на попередньому етапі. На даному етапі команда уточнює і деталізує цілі і результати проекту, а також склад робіт по ньому. На підставі цієї інформації команда формує календарний план і бюджет, оцінює ризики і виявляє зацікавлених сторін.

Eman 3. Розробка. Дана стадія реалізується не для всіх проектів - як правило вона є частиною фази планування. У фазі розробки, характерною для технологічних проектів, визначається конфігурація майбутнього проекту і / або продукту і технічні способи його досягнення. Наприклад в IT-проектах на даному етапі вибирається мова програмування.

Eman 4. Реалізація та тестування. На цій фазі відбувається основна робота по проекту - написання коду, зведення будівлі і таке інше. Дотримуючись розробленого плану створюється зміст проекту, проводиться контроль за обраними 
критеріями. У другій частині цієї фази відбувається тестування продукту, він перевіряється на відповідність вимогам замовника і зацікавлених сторін. У частині тестування виявляються і виправляються недоліки продукту.

Eman 5. Моніторинг $і$ завериення проекту. Залежно від проекту дана фаза може складатися 3 простої передачі замовнику результатів проекту або ж 3 тривалого процесу взаємодії з клієнтами щодо поліпшення проекту і підвищенню їх задоволеності, і підтримки результатів проекту. Останнє відноситься до проектів в області клієнтського сервісу і програмного забезпечення.

Проведення структуризації проекту, а саме виділення підцілей, пакетів робіт та робіт є важливим етапом. Основними підцілями є:

- розробити технічне завдання 3 замовниками, а саме 3 керівництвом та навчальним відділом Одеської національної академії харчових технологій;

- визначити програмні вимоги до інформаційної предметної області системи та функціональний розподіл системних вимог щодо апаратного та програмного забезпечення (ініціалізація веб-сервера, підключення до бази даних, вибір IDE, вибрати технічні засоби, визначитись з мовами програмування);

- розробити функціональні можливості (дизайн, верстка, програмування алгоритмів);

- завершити розробку та впровадити програмне забезпечення (тестування, розробка документації, інтеграція ПЗ 3 програмою «Розклад», тренінги з персоналом диспетчерської навчального відділу).

Перелік комплексно-підсумкових та елементарних робіт записано в табл. 1.

Таблиця 1 - Перелік комплексно-підсумкових та елементарних робіт проекту

\begin{tabular}{|c|c|c|c|}
\hline $\begin{array}{l}\text { № } \\
\text { ПI/II }\end{array}$ & $\begin{array}{c}\text { Комплексно-підсумкові } \\
\text { роботи }\end{array}$ & Елементарні роботи & Виконавці \\
\hline \multirow[t]{3}{*}{1.} & \multirow[t]{3}{*}{ Розробка технічного завдання } & $\begin{array}{l}\text { Складання документації, що } \\
\text { детально описує структурну } \\
\text { і поведінкову моделі проекту }\end{array}$ & \multirow{3}{*}{$\begin{array}{l}\text { Замовник, } \\
\text { спонсор, } \\
\text { керівник } \\
\text { проекту, } \\
\text { укладач } \\
\text { документації }\end{array}$} \\
\hline & & $\begin{array}{l}\text { Визначення дати кінцевого } \\
\text { релізу }\end{array}$ & \\
\hline & & $\begin{array}{l}\text { Виділення проміжних } \\
\text { результатів }\end{array}$ & \\
\hline \multirow[t]{3}{*}{2.} & \multirow[t]{3}{*}{$\begin{array}{l}\text { Створення дизайну та } \\
\text { навігації }\end{array}$} & $\begin{array}{l}\text { Створення дизайну головної } \\
\text { сторінки }\end{array}$ & \multirow{3}{*}{$\begin{array}{l}\text { Дизайнер, } \\
\text { керівник } \\
\text { проекту }\end{array}$} \\
\hline & & $\begin{array}{l}\text { Створення дизайну панелі } \\
\text { керування }\end{array}$ & \\
\hline & & $\begin{array}{l}\text { Розробка структури веб- } \\
\text { додатку та навігації }\end{array}$ & \\
\hline \multirow[t]{2}{*}{3.} & \multirow[t]{2}{*}{ Верстка макетів } & $\begin{array}{l}\text { Верстка дизайну головної } \\
\text { сторінки }\end{array}$ & \multirow{2}{*}{$\begin{array}{l}\text { Front-end } \\
\text { розробник, } \\
\text { керівник } \\
\text { проекту }\end{array}$} \\
\hline & & $\begin{array}{l}\text { Верстка дизайну панелі } \\
\text { керування }\end{array}$ & \\
\hline \multirow[t]{2}{*}{4.} & \multirow[t]{2}{*}{ Програмування алгоритмів } & Розробка бази даних & \multirow{2}{*}{$\begin{array}{l}\text { Back-end } \\
\text { розробник, } \\
\text { керівник } \\
\text { проекту }\end{array}$} \\
\hline & & $\begin{array}{l}\text { Опис проекту засобами мов } \\
\text { програмування }\end{array}$ & \\
\hline \multirow[t]{2}{*}{5.} & \multirow[t]{2}{*}{ Установка } & $\begin{array}{l}\text { Копіювання проекту на } \\
\text { робочий сервер }\end{array}$ & \multirow{2}{*}{$\begin{array}{l}\text { Back-end } \\
\text { програміст, } \\
\text { front-end } \\
\text { розробник }\end{array}$} \\
\hline & & Налаштування проекту & \\
\hline \multirow[t]{3}{*}{6.} & \multirow[t]{3}{*}{ Тестування та наладка } & $\begin{array}{l}\text { Виявлення синтаксичних і } \\
\text { логічних помилок проекту і } \\
\text { подальше їх усунення. }\end{array}$ & \multirow{3}{*}{$\begin{array}{l}\text { Front-end } \\
\text { розробник, } \\
\text { back-end } \\
\text { розробник, } \\
\text { тестувальник, } \\
\text { керівник } \\
\text { проекту, } \\
\text { укладач } \\
\text { документації }\end{array}$} \\
\hline & & $\begin{array}{l}\text { Розробка інструкцій } \\
\text { користувача }\end{array}$ & \\
\hline & & Проведення тренінгів & \\
\hline
\end{tabular}


Після того як розписали задачі - команда визначається зі строками. В програмі Gantt Project було створено новий проект. Далі було заповнено задачі та учасників проекту після чого було присвоєно задачі учасникам. На рис. 2 зображено список задач проекту. Було виконано оцінку часу виконання кожної задачі. Загальний строк виконання проекту близько 2-х місяців.

\begin{tabular}{|c|c|c|}
\hline Назва & Початок & Кінець \\
\hline Розробка технічного завдання & 01.10 .2021 & 05.10 .2021 \\
\hline Складання документації, що детально описує структурну і поведінкову моделі проекту & 01.10 .2021 & 03.10 .2021 \\
\hline Визначення дати кінцевого релізу & 04.10 .2021 & 05.10 .2021 \\
\hline Виділення проміжних результатів & 04.10 .2021 & 05.10 .2021 \\
\hline Затвердження Т3 з замовником & 06.10 .2021 & 07.10 .2021 \\
\hline Створення дизайну та навігації & 08.10 .2021 & 17.10 .2021 \\
\hline Розробка структури веб-додатку та навігації & 08.10 .2021 & 09.10 .2021 \\
\hline Створення дизайну головної сторінки & 10.10 .2021 & 17.10 .2021 \\
\hline Створення дизайну панелі керування & 10.10 .2021 & 17.10 .2021 \\
\hline Затвердження макетудиизайну з замовником & 18.10 .2021 & 19.10.2021 \\
\hline Верстка макетів & 20.10 .2021 & 24.10 .2021 \\
\hline Верстка дизайну головної сторінки & 20.10 .2021 & 24.10 .2021 \\
\hline Верстка дизайну панелі керування & 20.10 .2021 & 24.10 .2021 \\
\hline Затвердження верстки макету з замовником & 25.10 .2021 & 26.10 .2021 \\
\hline Програмування алгоритмів & 27.10 .2021 & 17.11.2021 \\
\hline Імпорт та створення таблищь БД & 27.10 .2021 & 29.10 .2021 \\
\hline Опис проекту засобами мов програмування & 30.10 .2021 & 17.11.2021 \\
\hline Установка & 18.11.2021 & 19.11.2021 \\
\hline Копіювання проекту на робочий сервер & 18.11.2021 & 18.11.2021 \\
\hline Налаштування проекту & 19.11.2021 & 19.11.2021 \\
\hline Тестування та наладка & 20.11.2021 & 28.11.2021 \\
\hline Виявлення синтаксичних і логічних помилок проекту і подальше їх усунення & 20.11.2021 & 23.11.2021 \\
\hline Розробка інструкцій користувача & 26.11.2021 & 27.11.2021 \\
\hline Проведення тренінгів & 28.11.2021 & 28.11.2021 \\
\hline Затведження проекту з замовником & 24.11 .2021 & 25.11.2021 \\
\hline
\end{tabular}

Рис. 2 - Список задач проекту з оцінкою часу

\section{6. Обговорення результатів}

Команда проекту та менеджер проекту завжди стикаються 3 двома основними аспектами: технічним та соціокультурним аспектами. Технічний аспект - це ті методології, інструменти які ми обираємо для управління, принципи, як часто ми збираємось та інше. Соціокультурний аспект - це є взаємодія всередині команди, зі спонсорами та замовниками. Можна вважати соціокультурний аспект важливішим за технічним, тому що без налагодженої взаємодії всередині команди - не буде успіху. Успішний проект - це проект в якому замовник завжди задоволений.

На рис. 3 представлено діаграму Ганта. Діаграма Ганта являє собою відрізки (графічні плашки), розміщені на горизонтальній шкалі часу. Кожен відрізок відповідає певній комплексній або елементарній роботі. Роботи розміщуються по вертикалі. Початок, кінець і довжина відрізка на шкалі часу відповідають початку, кінцю і тривалості завдання. На діаграмі Ганта також показується залежність між завданнями.

За допомогою Gantt Project можна слідувати за виконанням завдань, копіюванням їх статусів у процесі виконання. Цей інструмент настільки функціональний, що навіть дозволяє вказати, коли конкретний працівник був вихідним або іменував вільні дні. Задачі на рис. 3 побудовані послідовно, після певних робіт відбувається затвердження 3 замовником проекту.

На рис. 4 зображено відповідність задач та учасників проекту. За даним зображенням ми можемо відслідкувати занятість кожного суб’ єкта та переглянути на якому етапі він знаходиться. 

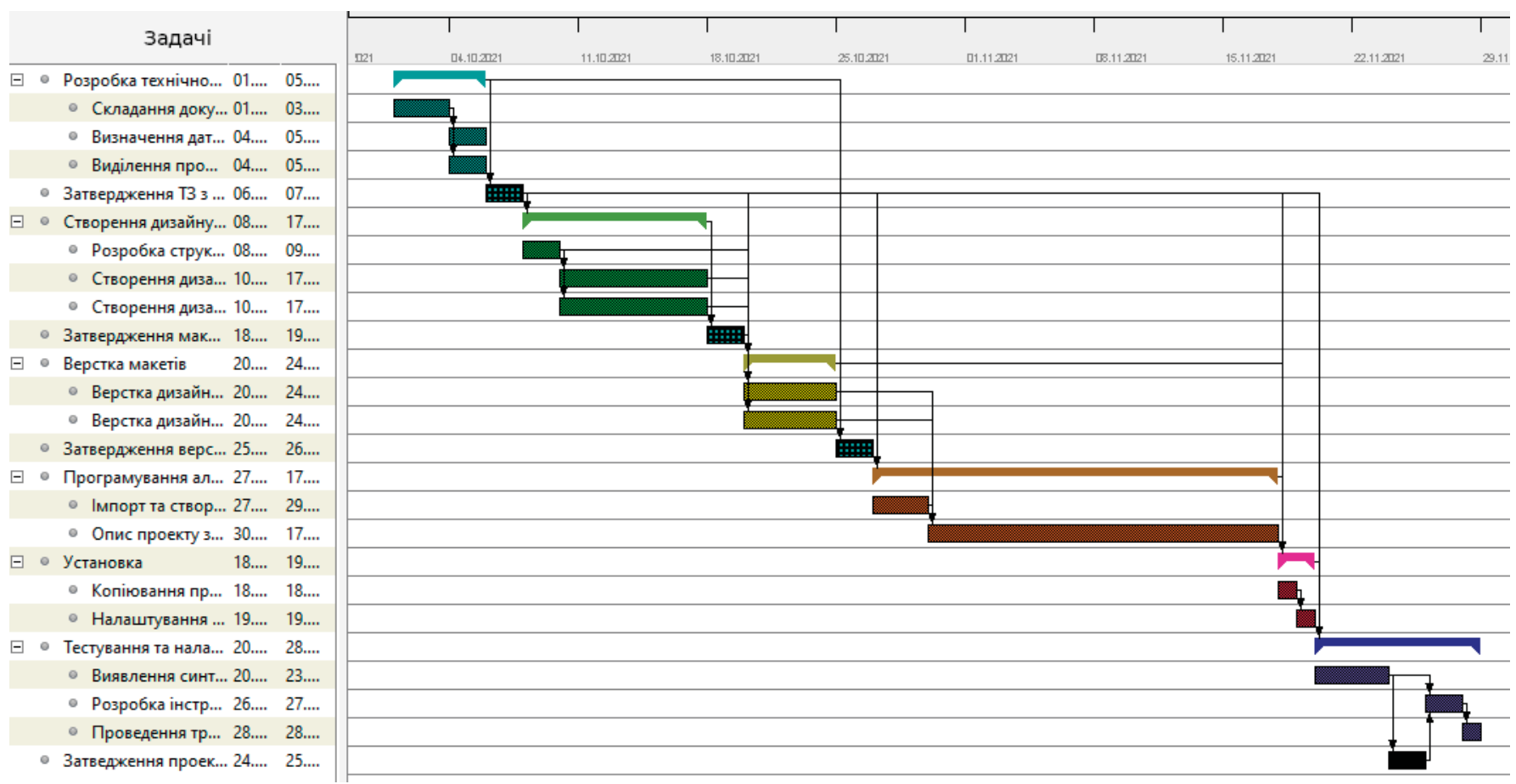

Рис. 3 - Діаграма Ганта

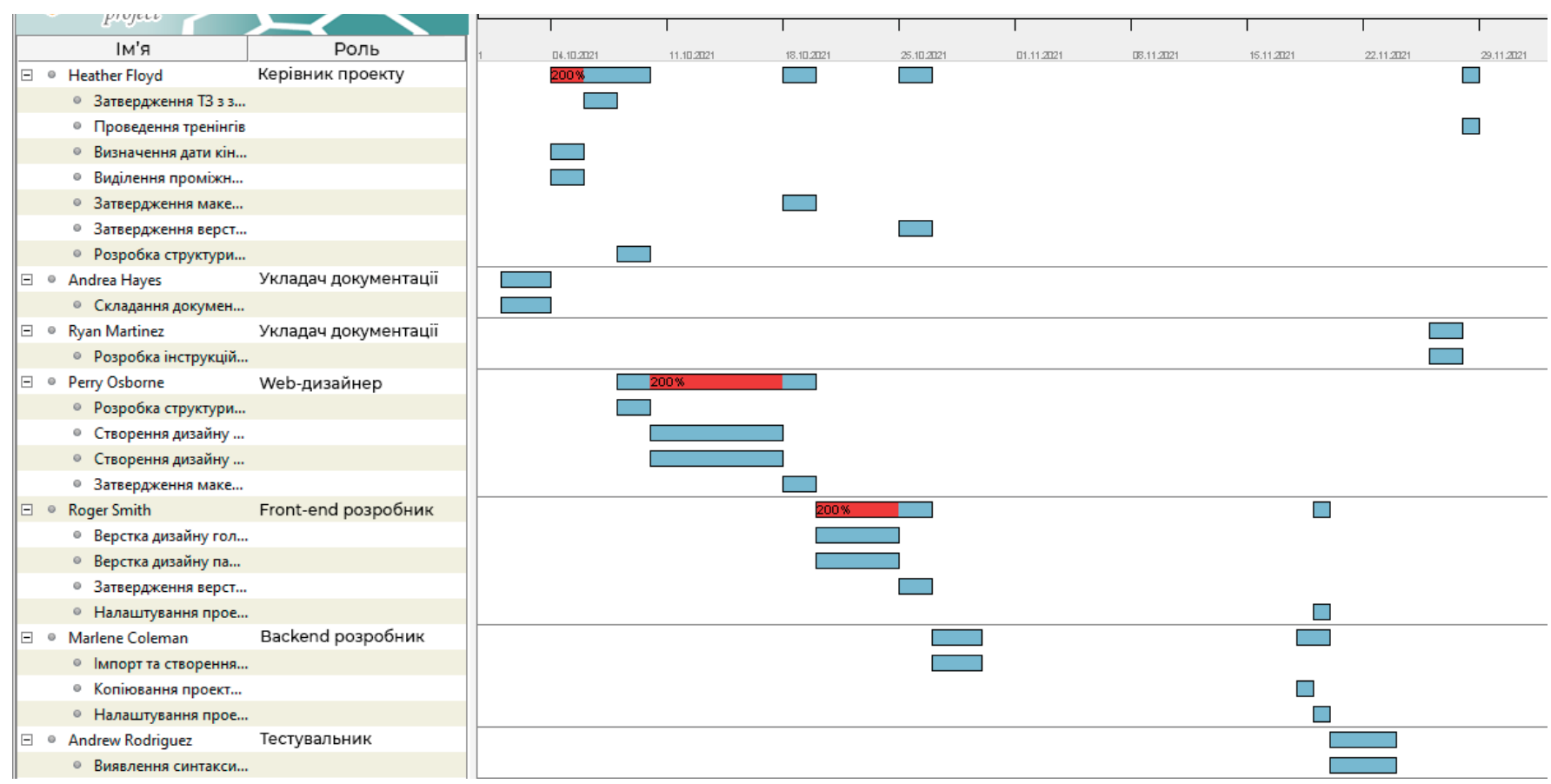

Рис. 4 - Учасники проекту

\section{7. Висновки}

В ході виконання даного дослідження було проведено проектний менеджмент для управління проектом розробки та впровадження програмного забезпечення автоматизованого формування розкладу навчальних занять для 3ВО. Було визначено особливості управління даним проектом та визначено тип проекту.

Було обрано каскадну модель життєвого циклу управління проектом. Важливим є те що, для успішного виконання проекту потрібно ретельно обговорити вимоги та функціонал програмного забезпечення 3 замовником. Всі етапи виконуються послідовно один за одним. Було сформовано список елементарних робіт та виділено комплексно підсумкові роботи, які потім було додано в задачі програми Gantt Project. Для кожної задачі було визначено строки виконання та виконавця. Gantt Project - це зручний інструмент для управління проектами, тому що він має можливість друкувати діаграми Ганта, надає можливість керівнику проекту слідкувати за ходом проекту в реальному часі та 
стежити за завантаженістю своєї команди. Використання даного інструменту дасть змогу реалізувати проект швидко, якісно і з оптимальними затратами ресурсів.

\section{Список використаних джерел}

[1]. O. Sakaliuk and F. Trishyn, "ANALYSIS OF PROCESS CREATION OF THE COURSES TIMETABLING", Automation of technological and business-processes, vol. 11, no. 2, pp. 30-35, 2019. DOI:10.15673/atbp.v11i2.1370.

[2]. O. Sakaliuk and F. Trishyn, "USING A GENETIC ALGORITHM TO SOLVE THE COURSES TIMETABLING CREATION PROBLEM", Automation of technological and business-processes, vol. 13, no. 2, pp. $22-28,2021$. DOI:10.15673/atbp.v13i2.2053.

[3]. A. Mishra and D. Mishra, "Software project management tools", ACM SIGSOFT Software Engineering Notes, vol. 38, no. 3, pp. 1-4, 2013. DOI:10.1145/2464526.2464537.

[4]. A. Walker, Project Management in Construction, 6th ed. West Sussex: Wiley Blackwell, 2015, p. 336.

[5]. J. Heagney, Fundamentals of Project Management, 1st ed. New York: American Management Association, 2016, p. 252.

[6]. С.В. Скороход, Управление ІТ проектами. Инструменты. Таганрог: ТТИ ЮФУ, 2011, с.182.

[7]. Г.В, тарченко, Управління проектами: теорія та практика. Чернігів: Брагинець О.В., 2018, с. 316.

[8]. "Сучасні методи управління проектами", Sgv.in.ua. [Online]. Режим доступу: https://sgv.in.ua/off-lifaq/25suchasni-metodi-upravlinnya-proektami. [Дата звернення: 04. Жовт. 2021].

[9]. "10 найкращих інструментів управління проектами", freexbcodes.com. [Online]. Режим доступу: https://freexbcodes.com/startap/10-najkrashhih-instrumentiv-upravlinnja-proektami/. [Дата звернення: 04. Жовт. 2021].

[10]. "ТОП інструментів управління проектами - Блог системи управління проектами Worksection", Worksection. [Online]. Режим доступу: https://worksection.com/ua/blog/top-management-tools.html. [Дата звернення: 04. Жовт. 2021].

\section{References}

[1].O. Sakaliuk and F. Trishyn, "ANALYSIS OF PROCESS CREATION OF THE COURSES TIMETABLING", Automation of technological and business-processes, vol. 11, no. 2, pp. 30-35, 2019. DOI:10.15673/atbp.v11i2.1370.

[2].O. Sakaliuk and F. Trishyn, "USING A GENETIC ALGORITHM TO SOLVE THE COURSES TIMETABLING CREATION PROBLEM", Automation of technological and business-processes, vol. 13, no. 2, pp. 22-28, 2021. DOI:10.15673/atbp.v13i2.2053.

[3].A. Mishra and D. Mishra, "Software project management tools", ACM SIGSOFT Software Engineering Notes, vol. 38, no. 3, pp. 1-4, 2013. DOI:10.1145/2464526.2464537.

[4].A. Walker, Project Management in Construction, 6th ed. West Sussex: Wiley Blackwell, 2015, p. 336.

[5].J. Heagney, Fundamentals of Project Management, 1st ed. New York: American Management Association, 2016, p. 252.

[6].S. Skorokhod, Upravleniye IT pryeektami. Instrumenty. Taganrog: TTI YuFU, 2011, c. 182.

[7].H.V, tarchenko, Upravlinnia proektamy: teoriia ta praktyka. Chernihiv: Brahynets O.V., 2018, c. 316.

[8]."Suchasni metody upravlinnia proektamy", Sgv.in.ua. [Online]. Rezhym dostupu: https://sgv.in.ua/off-lifaq/25suchasni-metodi-upravlinnya-proektami. [Data zvernennia: 04. Zhovt. 2021].

[9]." 10 naikrashchykh instrumentiv upravlinnia proektamy", freexbcodes.com. [Online]. Rezhym dostupu: https://freexbcodes.com/startap/10-najkrashhih-instrumentiv-upravlinnja-proektami/. [Data zvernennia: 04. Zhovt. 2021].

[10]. "TOP instrumentiv upravlinnia proektamy - Bloh systemy upravlinnia proektamy Worksection", Worksection. [Online]. Rezhym dostupu: https://worksection.com/ua/blog/top-management-tools.html. [Data zvernennia: 04. Zhovt. 2021]. 